\title{
Segmental Circular Necrosis of The Bowel
}

\author{
Shaposhnikov Veniamin Ivanovich* \\ Professor of surgical diseases, Vice Rector, Russia
}

Received: 無: September 10, 2018; Published: 制 September 21, 2018

*Corresponding author: Shaposhnikov Veniamin Ivanovich, Professor of surgical diseases, Vice Rector, Russia

\section{Annotation}

The author describes 11redko common observations of heavy forms of auto-immune allergic processes emerging in the form of a circular segmental-bowel necrosis. Describes the surgical treatment. Are modern views on etiology and pathogenesis of nonspecific ulcerative colitis, a form of which is considered a pathology. Work was of interest to clinicians in various fields of work.

Keywords: Circular; Segmental; Necrosis; Pathogenesis; Operative Treatment

\section{Introduction}

Ulcerative colitis (NSU) refers to the number of diffuse chronic recidivating diseases of the colon, which mainly affected its mucous membrane. Some patients of disease are extremely ma-lignant, with the development of segmental necrosis as thin and thick intestines [1-5]. NSU meets throughout the world. In year 3 to 15 of diagnosed new observations on 100000 of the population, and the incidence of reaches 50-80. Men and women have equally often. The first peak of the delectability of age from 20 years old do40, the second 60-70 years [2,6]. At pre-sent, there is no clear information about the etiology and pathogenesis of this disease. It is expected that the development of ulcerative colitis is the breakdown of immunological tolerance to intestinal antigens. The result is a loss of immunological control of inflammation in the wall of the small and large intestines [2,7]. It is believed that this pathological process normally resist low doses of endogenous gljukokortikosteroidov (GKS), that in a cage are associated with the specific gljukokortikosteroidnymi zitoplazmaticakimi receptors.

This complex enters the nucleus of the cell and is in contact with DNA elements in the region are glukokortikoida specific genes. The most often considered to be a hereditary predisposition to the development of autoimmune inflammation in the mucosa of the colon in response to sowing surface micro-organisms and viruses, as well as contact the impact food. This opinion is based on the frequent combination of NSU with other autoimmune processes $[3,8]$. The discovery of same in colon mucosa of IgG-antibody to epithelial cells and p-ANCA only strengthened the position of the supporters of this hypothesis. Completed studies to determine the ratio of t-lymphocytes in the mucosa of the colon indicate violation agents' interactions activated CD4 and CD8 lymphocytes. Normal epithelial cells stimulate the predominantly CD8-T cells. While at NSU they activate CD4 lymphocytes exclusively and is accompanied by IL-2 secretion of lymphokines and stimulation of macrophages in the complement system.

Identified and family history of NSU, with first-line relatives fall sick more often than the average population, as well as the risk factors they have clearly seen the use of oral contraceptives, as well as features nutrition and psychosocial problems $[3,5]$. Literature data suggest an important role of normal intestinal microflora in the adaptation reaction of human organism to the age changing his life $[3,8]$. In view of these data, the reason becomes clear when you change syndromic pathological development of microflora of the colon. At a young age caused for one reason or another, intestinal dysbiosis is accompanied by diarrhoea, coupled with the broodily process. Every fifth patient in this age group are marked with allergic dermatitis, occurring against the backdrop of autonomic expressed violations. Dysbacteriosis of the same link with a postponed intestinal infection and long treatment with antibiotics. Performed bacteriological researches in this group of patients indicate expressed growth suppression of Escherichia coli with a simultaneous settlement of the lumen of the colon of conditionally pathogenic microflora (Enterobacter-ria, Citrobacter, Klebsiella, Proteus, fungi kind Candida, gemolizirujushhie strains of Escherichia, etc.).

Individuals have the same maturity (40-59 years), in which there is persistent constipation alternating with diarrhea, bacterial painting Cala proportion of functionally defective (lactosenegative and enzymatically attenuated) strains of e. coli, which occurs against the backdrop of moderate decline bifidumbakterij growth. The same persons over the age of 60 years, suffering persistent constipation, the faces noted a sharp decline in the obligate micro-flora (Lactobacillus bifid and Lactobacillus) while increasing the level of conditionally pathogenic microflora [2]. 
Infections often cause the development and exacerbation of Ulcerative colitis, because one way or another damaged mucosa easily kontaminiruetsja pathogenic microflora $[3,8]$. NSU have detected symptoms of abenteric $20 \%$ of patients. They include Nodular Erythema, gangrenoznaya Pyoderma, inflammatory eye diseases, arthritis, ankylosing spondylitis, respiratory dysfunction, Myositis, Vasculitis, Glomerulonephritis, and other pathological processes outside the walls of the colon guts $[3,5]$. The purpose of isslevovanijaj Describe the clinical symptoms and treatment of segmental and circular bowel necrosis as a rare form of nonspecific ulcerative colitis.

\section{Materials and Methods}

Watched 118 patients with NSU, which entered the surgical Department with symptoms of acute peritonitis. During the operation $11(9.3 \%)$ of them diagnosed with segmental circular tissue necrosis of the small and large bowel from 3-4 cm to 90-100 $\mathrm{cm}$. The rest of the same 107 patients was struck only colon, with necrosis was micro perforations, and around the circumference of the bowel was limited to only one half of her walls. These patients have completed the Division of colon resection with overlay or end co-lostomy or ileostomy. Died 18 patients (15.2\%). Because of the rarity of the disease process, more thorough clinical analysis was subjected to 11 observations which revealed segmental necrosis of the small and large bowel. The age of these patients was from 35 up to 83 years (mean age $61 \pm 0.9$ years), 7 of them are men. All noted the acute development of disease and diagnosis was for the first time during this operation. 7 patients have predominantly been struck by the small intestine, while the kill zone alternated with patches of relatively healthy tissue.

Perforation occurred in the zone of necro-sis with the development of distributed horizon suppurative peritonitis. Thick same gut these 7 patients was significantly increased in all divisions and had multiple pockets of hemorrhages. Its wall was thickened.
The remaining 4 patients were both amazed and thin and large intestine. The modified sections of the intestine were rezecirovany with overlay or anastomoses [6,9], or end-Colo-ileostomy [5]. When the macroscopic and microscopic studies of remote divisions bowel changes were found characteristic of NSU. Mesenteric vascular patency was saved. In all patients the disease has developed against the backdrop of chronic intoxication (bad habits, medicament therapy), and chronic bacterial infections (pyodermas, chronic rhinitis, sinusitis, tonsillitis, fungal defeat feet and hands, etc.) It was found that all patients with adolescence suffered from constipation. The Chair was only a day, and sometimes through the 2-3 days. With age the constipation has become persistent nature and without enemas achieved defecation them failed. Patients often resorted to staging of salt, SOAP, oil and oth-er enemas, after which the pain appeared e left iliac region and after defecation tenesmus.

In the last year before the hospitalization in the stake appeared mucus and blood veins. For med-ical assistance. These changes in the Act of urinating associated with suhojadeniem, the struggle with obesity, alcohol intake, etc. 3 have patients whose colostomies were imposed, con-ducted active drainage of the abdominal cavity. All these patients were able to save. Active drainage of the abdominal cavity is carried out as follows (Figure 1). After resecetion of the Necrotizing Division colon, and all 3 observations it was left half colon, superimposed on the right half of the fistula limit poperechnoobodochnoj guts without tension dis-played her slice. Then carried out sanitation of the abdominal cavity and intubation of the small intestine from the stomach and rectum. Blend 4 chopped kontrapertury (both iliac and podrebernyh areas). Through these punctures in abdominal cavity injected perforated tubular plastic drains. Following this, the left and right of the navel made wound length $2.5-3.0 \mathrm{~cm}$, through which the abdominal cavity entered 2-e LaTeX containers of variable capacity. The most convenient containers made of latex surgical gloves, skylight which is tightly fixed frame ducts.

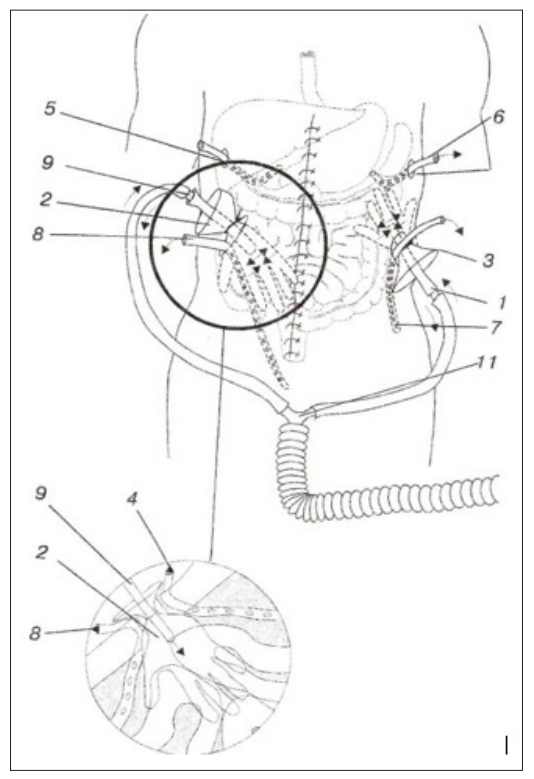

Figure 1: Active drainage of the abdominal cavity is carried out as follows. 
Above the surface of the skin remains only perchatochnoe ring seal and air duct. To conduct peritoneal lavage-dialysis drains and gloves on the sides of the germetizirovalis tissue wounds. This prevented the seepage of washing fluid from the abdominal cavity outwards during the procedure. Median zashivalas wound tightly. In the House drains connected to the measuring lines and ducts were plugged into to objomnomu HEPA. Set parameters for the operation of the respirator: volume one capacity 300 cube. see discharge pressure- $280 \mathrm{~mm}$ of water, and the reset is 0 . The multiplicity of cycles varies from 22 to 28 in 1 minutu. Preferred synchronization cycles at a frequency of respiratory excursion. In the case of surgery, this is accomplished by synchronizing two volumetric respirators. If you cannot sync with breathing, the multiplicity of standartiziruetsja cycles-cycle 22 per minute. The duration of the procedure using a volumetric respirator depends on strong recovery of intestinal peristalsis. Capacity of complex configuration, which is the glove to ensure both inflow and squeezing peritoneal exudate through drains and produce a kind of internal massage of the entire abdominal cavity with passive transfer and the squeezing of the entire gastrointestinal tract.

It promotes it gas and fluid that helps restore his Peristaltic activity. The most important positive property of this method is also restoring circulation in all tissues and organs of the abdominal cavity. Synchro-nize "intra-abdominal" massage with breathing, breathing creates a positive total pressure that dramatically increases the outflow of exudates on drainage. All these positive developments provide restore resistant peristalsis of the bowel during the 1-3 days. Lavage-dialysis lasted 2-3 days. Patients without going through the House, immediately diverted to the operating room. Created teams of 2-3 surgeons, anesthesiologist and transfuziologa After relative stabilization of blood pressure, run laparatomy. From the abdominal cavity washed over the malodorous muddy effusion. Bowel loops were covered with brownish-grey fibrin and brazed among yourselves in one conglomerate. After his separation, detected the source of peritonitis. Bowel resection and colostomy were made by ordinary methods. Operating patients there were in the intensive care unit, where and internal abdominal massage according to the methodology described above. Peritoneal dialysis was performed in the following way.

At the end of operations in the abdominal cavity joined 100$200 \mathrm{ml}$ of fat emulsion is recommended for injecting. Then, begin instillation of dializirujushhih solutions. Crucial is the alternation of every 4:00 Jet and a drip of different fluids, with meticulous monitoring of their balance. The lower two levels fall below the drainage bed in measuring containers, and to two tops joined the system for intravenous fluids. Lavage-dialysis begins with Jet into the abdominal cavity through the two upper drainage 200-300 $\mathrm{ml} 0.25 \%$ solution novokaina, while controlled by Jet discharge of liquid from the lower drainages. After you enter the mix furazilina with hydrogen peroxide (300-350 ml furazilina $+100-150 \mathrm{ml}$ of $3 \%$ solution of hydrogen), and then $300-500 \mathrm{ml} \mathrm{5 \%}$ glucose solution or 500-1000 ml kristalloidnogo complex solution. Upon termination of the Jet dializata income from the abdominal cavity, i.e. the completion of the first cycle of the lavage, drip begins the introduction into the abdominal cavity $1.5 \%$ solution of sodium chloride, or more complex salt solution that lasts 4:00. At this time is cleansed of toxins and nedookislennyh homeostasis of metabolic products, i.e. committed dialysis.

Then everything repeats itself. During the second cycle of this process, 2-3 times daily dializata composition included antibioticsbased antibiograms, as well as $300-500 \mathrm{ml}$ 5\% glucose solution and 100-150 $\mathrm{ml}$ of fat emulsion. They increase the sorption of toxins from the abdomen (due to increased osmotic perfuzata capacity) and monitors the progression of the process in the abdominal cavity. Scheme of active drainage of the abdominal cavity, where: 1-frame tube. introduced in the opening rubber container, 2-ringseal glove, 3-drainage tube held beside the glove in the left side of the abdomen, Channel 4-drainage tube held beside the glove over the liver, 5-the same pipe carried out under liver, 6-the same tube held to the spleen, 7-intraperitoneal end tube held in the left side channel 8-same tube introduced into the cavity of the lesser pelvis, 9-frame tube introduced into the gloves, 10-11-tee, connecting both frame tubes with hose breathing respirator.

\section{Results}

Of 11 patients with circular segmental necrosis of the intestine during 1-3 weeks after surgery died 7 persons (lethality conditionally $64 \%$ ), with 5 of them were carried out repeated operations (from 2 to 5). Cause of death all have served as multiple organ failure, which developed on the background of peritonitis. Resort to primary resection was the alleged well-being of sshivaemyh tissue-they were outwardly healthy appearance. But on the 3-4 day after the operation from the abdominal cavity for drainage started to stand out intestinal con-tents. Patients rapidly deteriorated despite relaparotomy. 4 patients survived, of which 3 have conducted active drainage of abdominal cavity and 1 is affixed the end colostomy. However, all 4 in the treatment of bowel necrosis, progression was observed with 2 came the end of necrosis of the bowel, going to colostomy, 2 others have had necrotized previously healthy loop of the small intestine. Each of them had to run from 3 to 8 relaparotomy. The end result of the entire small intestine left on 40-80 cm proximal and distal $\mathrm{cm}-20-50$ its divisions. Intensive complex treatment duration ranged from 48 to 77 bed-days.

\section{Discussion}

Circular segmental necrosis of the intestine is related to specific type of non-specific ulcerative colitis. Surgical treatments allow you to only remove diseased tissues and even correct peritonitis, but they are not able to remove from the organism immune complexes, which after the operation continue to destroy the mucous membranes of the intestine. For this reason, the most effective means to combat this extremely serious illness is prevention. It should be included ways to treat chronic microbial and fungal skin diseases, throat, sinuses and other organs and tissues. Play an important role and methods of elimination of koprostaza refusal to enemas because they result in dislocation of pathogenic flora from the channel anus into the colon, which is accompanied by izgyazwleniem its mucous membrane. You need to avoid and bad habits and ill-considered violations of diet. 


\section{Conclusion}

Now developed effective surgical ways to treat peritonitis developed putrid due to the collapse of the wall of the colon. To this method of treatment can be attributed to the active drainage of the abdominal cavity. However, it does not remove from the organism immune complexes, which continue to be formed and destroy mucous shell of the colon. You can only warn complex social measures aimed at the timely treatment of chronic intoxications of microbial and fungal skin lesions and other integumentary tissue, as well as correction of impaired functions of the intestines, etc.

\section{References}

1. Vorobev GI (2006) Atainable satisfactory results of surgical treatment of ulcerative colitis? 2(16): 34-42.

2. Golovenko OV (2006) Clinical features of ulcerative colitis in patients older. Coloproctology 2(16): 21-24.

3. Zhelnova TI (2003) Kandidozny dysbacteriosis of the intestine. Clinical features current issues of Coloproctology. Proceedings of the $1^{\text {st }}$ Congress of coloproctologists of Russia, Samara pp. 423-424.

\section{ISSN: 2574-1241}

DOI: $10.26717 / B J S T R .2018 .09 .001773$

Shaposhnikov Veniamin I. Biomed J Sci \& Tech Res

CC (i) This work is licensed under Creative

Submission Link: https://biomedres.us/submit-manuscript.php
4. VT Ivashkina, FI Komarova SI, Rapoport M (2001) Quickstart to Gastroenterology House of m-Lead p. 458.

5. LlKapuller, TL Mikhailov, VVVeselov, IL (2005) Place nedifferenciruemogo nonspecific colitis in the spectrum of inflammatory bowel disease Coloproctology 4(14): 33-34.

6. Sekachev MI (2003) Modern aspects of treatment of nonspecific ulcerative colitis; the results of evidence-based medicine $3: 18-22$.

7. Caliph IL (2006) Principles of treatment of ulcerative colitis (recommendations of the Russian study group on inflammatory bowel disease 3(17): 31-34.

8. Yakovleva OG (2003) Mikrobiotenoz bowel syndrome in different age groups. Proceedings of the $1^{\text {st }}$ Congress of coloproctologists of Russia, Samara pp. 439-441.

9. Stack WA, Long RG, Hawkwy CJ (1998) Short-and long-term outcome of patients been pre-treated with cyclosporine for severe acute ulcerative colitis. Aliment Pharmacologic There 12: 973-978.

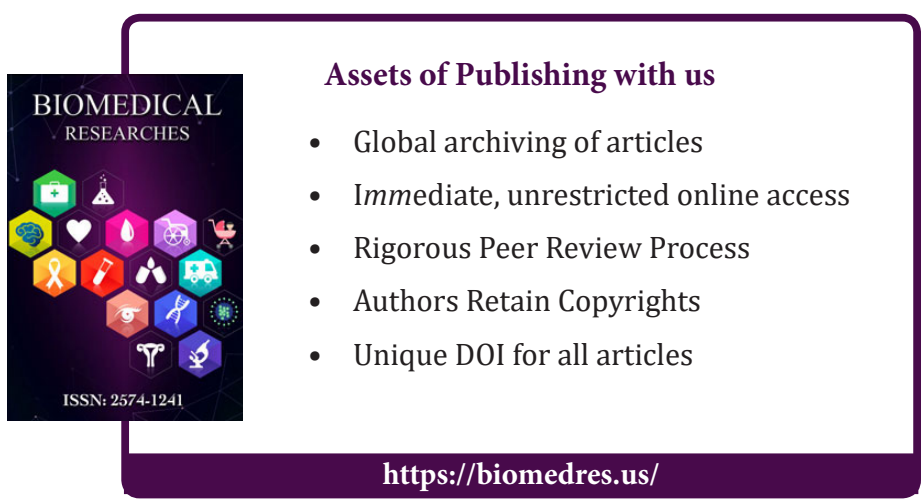

